\title{
Impact of work environment perceptions and communication satisfaction on the intention to quit: An empirical analysis of nurses in Saudi Arabia
}

\author{
Abdulaziz M Alsufyani ${ }^{\text {Corresp., } 1,2}$, Khalid E Almalki $^{3}$, Yasir M Alsufyani ${ }^{4}$, Sayer M Aljuaid ${ }^{2}$, Abeer M Almutairi $^{5}$, \\ Bandar $O$ Alsufyani ${ }^{6}$, Abdullah S Alshahrani ${ }^{7}$, Omar G Baker ${ }^{1}$, Ahmad Aboshaiqah ${ }^{1}$ \\ ${ }^{1}$ College of Nursing, King Saud University, Riyadh, Saudi Arabia \\ 2 Comprehensive Rehabilitation Center, Ministry of Human Resources and Social Development, Taif, Saudi Arabia \\ 3 Primary Health Care Center, Ministry of Health, Riyadh, Saudi Arabia \\ ${ }^{4}$ College of Nursing, King Khaled University, Abha, Saudi Arabia \\ 5 King Fahad Specialist Hospital, Ministry of Health, Buridah, Saudi Arabia \\ 6 King Abdulaziz Specialist Hospital, Ministry of Health, Taif, Saudi Arabia \\ 7 Ahad Rufidah Hospital, Ministry of Health, Asser region, Saudi Arabia \\ Corresponding Author: Abdulaziz M Alsufyani \\ Email address: A.M.Alsofyani2@hrsd.gov.sa
}

Objective: In consideration of the current nursing shortage in Saudi Arabia, we aimed to investigate the association among perceptions of work environment, communication satisfaction, and intentions to quit nursing profession among nurses. In addition, we aimed to investigate the mediating effect of communication satisfaction on the association between nurses' perception of work environment and their intentions to quit nursing profession.

Methods: This predictive correlational study was conducted at one of the major hospitals in Saudi Arabia from January 2020 to March 2020. It included a convenience sample of 367 full-time registered nurses who completed three types of close-ended questionnaires. We used IBM SPSS version 24.0 to analyze the collected data. Regression analyses were used to test the study's hypotheses. All regression assumptions were assessed and confirmed. Significance for all tests was set at $p \leq .05$.

Results: The findings indicated an affirmative association between work environment perception and communication satisfaction $(b=.764, p<.05)$ among nurses. In addition, findings showed that work environment perception $(b=-.187, p<.05)$ and communication satisfaction $(b=-.226, p<.05)$ have negative impacts on the nurses' intentions to quit; indicating that as work environment perception or communication satisfaction increases, the intention to quit decreases among nurses. Further, a mediation effect of communication satisfaction on the relationship between work environment perception and intention to quit was confirmed.

Conclusion: This study presents a novel conceptual framework developed based on the literature about the predisposing factors for nurses' intentions to quit nursing profession. The findings highlighted that work environment perception and communication satisfaction among the most contributing factors for nurses' resignation. Effective communication was established as a crucial factor for establishing attractive and healthy working environment. Nursing managers can benefit by applying these findings to develop appropriate strategies to inhibit the shortage of nurses in Saudi Arabia.

PeerJ reviewing PDF | (2020:07:51122:2:0:NEW 6 Jan 2021) 


\section{Impact of Work Environment Perceptions and}

\section{Communication Satisfaction on the Intention to Quit:}

\section{An Empirical Analysis of Nurses in Saudi Arabia}

4

5 Abdulaziz M. Alsufyani ${ }^{1,2^{*}}$, Khalid E. Almalki ${ }^{3}$, Yasir M. Alsufyani ${ }^{4}$, Sayer M. Aljuaid ${ }^{2}$, Abeer

6 M. Almutairi ${ }^{5}$, Bandar O. Alsufyani ${ }^{6}$, Abdullah S. Alshahrani ${ }^{7}$, Omar G. Baker ${ }^{1}$, Ahmad

7 Aboshaiqah $^{1}$

$9{ }^{1}$ College of Nursing, King Saud University, Riyadh, Saudi Arabia

$10{ }^{2}$ Comprehensive Rehabilitation Center, Ministry of Human Resources and Social Development,

11 Taif, Saudi Arabia

$12{ }^{3}$ Primary Health Care Center, Ministry of Health, Riyadh, Saudi Arabia

$13{ }^{4}$ College of Nursing, King Khaled University, Abha, Saudi Arabia

$14{ }^{5}$ King Fahad Specialist Hospital, Ministry of Health, Buridah, Saudi Arabia

$15{ }^{6}$ King Abdulaziz Specialist Hospital, Ministry of Health, Taif, Saudi Arabia

${ }^{7}$ Ahad Rufidah Hospital, Ministry of Health, Asser region, Saudi Arabia

* Corresponding Author:

21 Abdulaziz M. Alsufyani

Email address: A.M.Alsofyani2@hrsd.gov.sa 


\section{Abstract}

24 Objective: In consideration of the current nursing shortage in Saudi Arabia, we aimed to

25 investigate the association between perceptions of work environment, communication

26 satisfaction, and intentions to quit the nursing profession, among nurses. In addition, we aimed to

27 investigate the mediating effect of communication satisfaction on the association between

28 nurses' perception of work environment and their intentions to quit the nursing profession.

29 Methods: This predictive correlational study was conducted at one of the major hospitals in

30 Saudi Arabia from January 2020 to March 2020. It included a convenience sample of 367 full-

31 time registered nurses who completed three types of close-ended questionnaires. We used IBM

32 SPSS version 24.0 to analyze the collected data. Regression analyses were used to test the

33 hypotheses. All regression assumptions were assessed and confirmed. Significance for all tests

34 was set at $p \leq .05$.

35 Results: The findings indicated an affirmative association between work environment

36

37

38

39

40

41

42

43

44

45

46

47

48

49

50

51

52 perception and communication satisfaction $(b=.764, p<.05)$ among nurses. In addition, findings showed that work environment perception $(b=-.187, p<.05)$ and communication satisfaction $(b=$ $-.226, p<.05$ ) have negative impacts on the nurses' intentions to quit; indicating that, as work environment perception or communication satisfaction increases, nurses' intention to quit decreases. Further, a mediation effect of communication satisfaction on the relationship between work environment perception and intention to quit was confirmed.

Conclusion: This study presents a novel conceptual framework that is developed based on the literature about the predisposing factors for nurses' intentions to quit the nursing profession. The findings highlighted that, factors like work environment perception and communication satisfaction contribute the most to nurses' resignation. Effective communication was established as a crucial factor for establishing attractive and healthy working environment. Nursing managers can benefit by applying these findings to develop appropriate strategies to inhibit the shortage of nurses in Saudi Arabia.

Keywords. Communication Satisfaction, Intention to Quit, Nurses, Work Environment. 


\section{Introduction}

54 In the Kingdom of Saudi Arabia, expenditure on healthcare keeps on heightening. This is

55 because health organizations are the central aspects of a healthcare system in Saudi Arabia as

56 they significantly affect the health of community. Nurses are among the largest and crucial

57 workforces within health care organizations; they are accountable for guiding and providing

58 optimum care. According to Oliveira et al. (2017), concerns that adversely influence nurses

59 elevate the probability of challenges in the delivery of optimal healthcare services. One of these

60 challenges is nursing shortage which is dominant in Saudi Arabia (Aboshaiqah, 2016; Alsufyani

61 et al., 2020).

62 However, it was established that nursing shortage was preceded by nurses' intentions to quit the

63

64

65

66

67

68

69

70

71

72

73

74

75

76

77

78

79

80

81

82

83 profession. In addition, literature reports many factors linked to the nurses' resignation. For instance, Nantsupawat et al. (2016) stated that, intention to quit nursing profession exacerbates by stressful work environment and poor communication climate and strategies. In addition, Özer et al. (2017) established that nurses' satisfaction about work environment and communication climate within their healthcare organizations play an important role in their intentions to leave their jobs.

On the other hand, working environment constitutes a fundamental aspect for nurses' effective perception and competent delivery of care. In this context, work environment entails the social, physical, and psychological factors that influence and make-up the working conditions (Raziq \& Maulabakhsh, 2015). In addition, work environment was defined by Kohun $(2005$, p. 27) as "the combination of efficiency factors, actions, and possible challenges associated with the performances and activities of individuals". Precisely, every element of this relationship is included in the organizational environment of individuals and their work setting (Tsai, 2011). The objective of building healthy and stable work environment is to enhance the quality of health services through retaining competent nurses and encouraging individuals' use of their skills, knowledge, and existing resources effectively and efficiently.

Falatah and Conway (2019) postulate that a poor workplace environment results in stress and dissatisfaction which increases employees' intentions to quit. Workplace factors such as working hours, administrative style, perceived workload, coworkers support, and sharing in decisionmaking fundamentally influence the decision of employees to remain or leave their nursing jobs (Abdien, 2019; Al-Jenaibi, 2010; Masum et al., 2016). In addition, Admi et al. (2018) pointed

Peer) reviewing PDF | (2020:07:51122:2:0:NEW 6 Jan 2021) 
84 out that a poor work environment causes demoralization, dissatisfaction, and frustration. Further, 85 problems in the working environment are worsened by a lack of communication, which, in turn, 86 leads to greater intentions to quit.

87 Communication is a social-sentimental status that strengthens interpersonal relationships, 88 collaborative teamwork, and interactions. Communication also leads satisfaction in the 89 workplace; it encompasses the distribution of information with, and among personnel (Hua \&

90 Omar, 2016). Communication satisfaction is demonstrated as the level to which a person is 91 satisfied with different elements of organizational interaction including work knowledge, 92 personal feedback, interdepartmental communication, horizontal communication, 93 communication with supervisors, the communication climate, and media quality (Alshammari,

94 Duff \& Guilhermino, 2019; Andersson, 2018). Poor communication results in information asymmetry and often, workplace conflicts which exacerbate misunderstanding between employers and employees. Poor communication in nursing environment results in poor collaboration among team members in a unit, which adversely affects the quality of care offered to the patients. In addition, it deteriorates nurses' attachment to the organization provoking their willingness to leave the nursing profession (Doleman et al., 2020).

The intention to quit the nursing profession among nurses in Saudi Arabia has gained more attention recently. Unfortunately, many of these studies showed massive and terrible rates of intentions of quitting among nurses. For instance, Suliman (2009) reported that the highest rate of intention to quit was $77.1 \%$ among bedside nurses, followed by $38 \%$ among nurse managers. Al-Ahmadi (2014) also reported high rate of turnover intentions among nurses in Saudi Arabia (60\%). Surprisingly, the findings of Al-Ahmadi (2014) were congruent with a study conducted by Saeed (1995) 25 years ago in Riyadh, Saudi Arabia. More recently, a study conducted by Alonazi and Omar (2013) showed that the majority of the sample (75\%) showed intentions to leave within 24 months. In this regard, Al-Zayyer (2003) estimated that the average length of expatriate nurses' stay in their jobs in Saudi Arabia was 43 months. In addition, Filipino nurses, followed by Indian nurses had high rate of intentions of quitting the nursing profession in Saudi Arabia (Albougami et al., 2020).

112 However, across the world, the impacts of working environment perception and communication 113 satisfaction on nurses' intentions to quit have been documented. In contrary, although Saudi 114 Arabia is currently experiencing shortage of nursing workforce and high rates of nurses with 
115 intentions to leave the profession, these variables have been scantly investigated. Therefore, this 116 study intends to examine the association between nurses' perceptions of work environment, 117 communication satisfaction, and their intentions to quit the nursing profession in King Faisal 118 Medical Complex (KFMC), Saudi Arabia. In addition, this study aims to investigate the indirect 119 effect of nurses' work environment perception on their intentions to quit through communication 120 satisfaction. Consistent with the conceptual framework which guides this study, the following 121 hypotheses were examined:

$122 \mathbf{H}_{1}$. Nurses' perceptions of their work environment significantly predicts their intentions to quit 123 nursing profession.

$124 \mathbf{H}_{2}$. Nurses' perceptions of their work environment significantly predicts their satisfaction about 125 communication in their institution.

$126 \mathbf{H}_{3}$. Nurses' satisfaction about communication in their institution significantly predicts their 127 intentions to quit nursing profession.

$128 \mathbf{H}_{4}$. Communication satisfaction acts as a mediator between Nurses' perception of work 129 environments and their intentions of quitting

130

\section{Theoretical \& Conceptual Framework}

132 The model of nurse turnover proposed by Lake (1998) as shown in Figure 1, was used to develop 133 the study's conceptual framework. This model emphasizes nurses' intention to quit and 134 personnel turnover as the main outcome variable. Job opportunity, individual factors, and work135 related factors were included in the initial stage, while clinical autonomy and satisfaction were 136 included in the middle phase of the affective responses. In the last stage of the framework, the 137 actual turnover was resulted as an outcome of intention to quit the nursing profession.

We also added some new variables found in previous studies to modify Lake's nurse turnover model to discuss the relationship between intention to quit and nurses' work environment perception as shown in Figure 2. This new model considers organizational factors as nursing 142 work environment and affective responses to the job as communication satisfaction. This model

143 is drawn based on the organizational factors and affective responses leading toward nurses' 144 intentions to quit. 


\section{Materials \& Methods}

\section{Research Design and Setting}

148 This predictive correlational study was conducted at King Faisal Medical Complex in Taif, Saudi 149 Arabia throughout the cross-sectional period from January 2020 to March 2020. This facility is 150 known as one of the finest major hospitals in Saudi Arabia with a capacity of 800 beds.

151

152

153

154

155

156

157

158

159

160

161

162

163

164

165

166

167

168

169

170

171

172

173

174

175

176

\section{Sample and Population}

Nurses were recruited from King Faisal Medical Complex using a convenience sampling technique. Staff nurses included in this study were those with a minimum of two years of experience designated to work at patients' bedsides. Nurses were included if they had a valid working license as a nurse by the Saudi Commission for Health Specialties and worked as fulltime staff nurse. Exclusion criteria were paramedics, intern nurses, educators, managers, supervisors, and dependent nurses under supervision. In terms of sample size, a prior sample size estimation was calculated using $95 \%$ power, $\alpha=0.05$, and medium effect size $(0.15)$ with linear multiple regression: Fixed model, $\mathrm{R}^{2}$ deviation from zero as the statistical basis of the calculation using $\mathrm{G}^{*}$ Power 3.1. ${ }^{\mathrm{TM}}$. As a result, the calculated sample size of 107 was deemed adequate to produce statistical differences.

\section{Research Instruments}

Three instruments were used in their original languages (English); including Practice Environment Scale of the Nursing Working Index (PES-NWI) (Lake, 2002); Communication Satisfaction Questionnaire (CSQ) (Downs \& Hazen, 1977); and Intention to Quit Scale (Cammann, 1979). These instruments were covered with an appropriate socio-demographic questionnaire.

\section{Socio-demographic Questionnaire}

Part of the survey used in this study included demographic profiles of the participants. Nurses' gender, age, nursing work experience, and nationality were assessed.

\section{Practice Environment Scale of the Nursing Work Index (PES-NWI)}

The PES-NWI was used in the survey to examine the nurses' perception about the real work environment. The PES-NWI comprises five subdomains and a total of 31 items: nursing foundations for quality of care $(n=10)$, nurse participation in hospital affairs $(n=9)$, leadership 
177 and support of nurses $(n=5)$, staffing and resource adequacy $(n=4)$, and collegial nurse-

178 physician relations $(n=3)$. A four-point Likert scale was used to measure the items of the PES-

179 NWI, from strongly disagree $=1$ to strongly agree $=4$. Previously, Almuhsen et al. (2017)

180 verified the validity and reliability of the scale, which vary from 0.87 to 0.96 . In addition, this

181 instrument was used in its original language. In this study, Cronbach's Alpha coefficient

182 indicated the reliability of the PES-NIW as $\alpha=.94$.

183 Communication Satisfaction Questionnaire (CSQ)

184 Downs and Hazen (1977) introduced a communication satisfaction questionnaire, including 25

185 questions from five sub-dimensions: organizational feedback, communication with a supervisor, 186 communication climate, media quality, and organizational integration. A five-point Likert scale 187 is used to measure the questionnaire items, from $1=$ strongly disagree to $5=$ strongly agree.

188 Previously, Greenbaum, Clampitt, and Willihnganz (1988) found internally reliable and 189 consistent Cronbach's alpha scores across all organizations. In this study, Cronbach's coefficient 190 alpha calculated for the reliability of the CSQ and found to be $\alpha=.91$.

\section{The Intention to Quit Scale}

192 Cammann et al. (1979) developed a scale for measuring employees' intentions to quit. The scale 193 is scored using a five-point Likert scale, ranging from $1=$ strongly disagree to $5=$ strongly 194 agree. This questionnaire has been used in previous studies and its inter-reliability has been 195 established, varying from 0.83 to 0.92 . In the present study, the reliability of this scale was found 196 to be appropriate and valid with Cronbach's Alpha coefficient of $\alpha=.89$.

197

198 Ethical Approval

199 Ethical approval from an institutional review board was obtained from the Saudi Ministry of 200 Health, ref. No. HAP-02-T-067. Permission to conduct this study was granted by the nursing 201 management office of the King Faisal Medical Complex. The informed consents of the 202 participants' agreement to participate in this study and their agreement to the researcher using 203 their drawn data were gained. This study was consistent with the ethical principles of the 204 Declaration of Helsinki. Declaration of Helsinki is a set of ethical principles concerning 205 protecting the human beings in researches which was developed by the World Medical 206 Association (WMA, 2013). 


\section{Data Collection Procedure}

209 Data were collected during a three-month period from January 2020 to March 2020. The

210 participants completed the questionnaires and returned them to the designated place of

211 submission after first receiving guidance about the study objectives and providing their written

212 consent to participate. All participants were asked to submit their completed questionnaires

213 within five days. Submissions were received in collection boxes allocated for this purpose at the

214 KFMC.

215

\section{Data Analysis}

217 We used the IBM Statistical Package for Social Sciences (SPSS) version 24.0 to analyze the 218 collected data. The nurses' demographic details were presented through descriptive statistics. As 219 the data was normally distributed, the relationships between communication satisfaction, 220 intention to quit, and work environment were determined using Pearson's Correlation coefficient 221 ( $r$ ). Regression assumptions (normality, homoscedasticity, linearity, independence of errors, and 222 multicollinearity) were assessed to present valid results. Normality was assessed using normal 223 probability-probability $(P-P)$ plot of residuals. As the assumptions of homoscedasticity and 224 linearity relate to errors (Filed, 2018), they were assessed by plotting the predicted values versus 225 errors (zpred vs. zresid) on a scatterplot. Further, independence of errors was assessed using Durbin-Watson test for each model. Absence of multicollinearity was assessed through screening correlation matrix and Variance Inflation Factor (VIF).

The study's objectives were addressed using Baron and Kenny's (1986) proposed four-step approach to determine the presence of a mediation effect after confirming the presence of zeroorder relationships among the study variables. This four-step approach requires conducting three simple linear regression (SLR) analyses as step 1,2, and 3; to confirm the presence of zero-order relationships among the study's variables (Baron \& Kenny, 1986). As significant relationships from step 1 through step 3 are confirmed, the researcher proceeds to step 4 which requires conducting multiple linear regression (MLR) analysis with force entry technique for the predictor and intervening variables predicting the outcome variable. If the results of model 4 show that the predictor variable is no longer significant when a mediator variable is controlled, the finding 237 indicates a full mediation effect; if the predictor is still significant and a significant reduction in 
238 its relationship with the outcome variable has occurred, the findings supports a partial mediation 239 effect (Baron \& Kenny, 1986).

240 Simple linear regression analyses were conducted with the equation of $y=\alpha+b x$, where is " $y$ "

241 denoted for the predicted value of the dependent variable; " $x$ " denoted for the independent

242 variable; " $b$ " is slope of the line; and " $a$ " is $y$-intercept (Gray, Grove, \& Sutherland, 2017). In

243 addition, the equation used for MLR analysis was as follows: $y=a+b_{1} x_{1}+b_{2} x_{2}$ (Shultz,

244 Whitney, \& Zickar, 2014); where is " $y$ ” denoted for the predicted value of the dependent

245 variable; " $a$ " denoted for $y$-intercept; " $b_{1}$ " is the regression coefficient of the predictor variable

$246\left(x_{1}\right)$; and " $b_{2}$ " is the regression coefficient of the mediator variable $\left(x_{2}\right)$. The acceptable

247 probability value for all the statistical analyses was determined as $p \leq .05$.

\section{Results}

250 Of the 793 full-time nurses at the King Faisal Medical Complex, 500 received questionnaires and 251367 completed surveys were returned, representing a response rate of $73.4 \%$. Table 1 shows the 252 demographic profile of the participants. The majority of the participants were female (78.7\%), 253 and their ages ranged from 31-40 years. Most nurses (56.1\%) were in the "other" category of 254 specialization, followed by OB/GYN, Med/Surg, and "critical," categories at 19.3\%, 15.6\%, and

255

256

257

258

259

260

261

262

263

264

265

266

267

268

$9.0 \%$, respectively. Additionally, nurses of many nationalities participated in this study, including Filipino (41.7\%), Indian/Pakistani (25.3\%), and Saudi (23.7\%); “other nationalities" constituted $9.3 \%$ of the sample.

[Table 1 here]

Table 2 shows that out of these three factors, the mean score for work environment $(3.72 \pm 0.63)$ was greater compared to the other two factors. The satisfaction of nurses regarding communication levels and work environment were moderate. Additionally, a moderate level of probability was reported for intentions to quit among nurses $(2.47 \pm 1.38)$. A positive and significant relationship was revealed between work environment and communication satisfaction $(r=.613 ; p<.05)$. These findings confirm the absence of multicollinearity between the predictors as their relationship was $<0.8$ and $>0.3$. In addition, the association between work environment perception and the intention to quit was found to be negative and significant $(r=$ $.702 ; p<.05)$. Furthermore, the findings indicated that nurses' intentions to quit had inversely significant relationship with their communication satisfaction $(r=-.581 ; p<.05)$. 
270 The findings of regression assumptions tests showed no assumption was violated. Figure 3 shows

271 that the residuals were normally distributed as they conformed to the fixed diagonal line of

272 normality shown in the plot. In addition, the result of plotting the predicted values versus errors

273 (zpred vs. zresid) on a scatterplot showed a random array of dots; indicating that the data met

274 homoscedasticity and linearity assumptions of regression test. In addition, the absence of

275 multicollinearity was confirmed by the result of VIF test which showed no variable has VIF

276 greater than 10. Further, the results of Durbin-Watson test confirmed the autonomy of residuals

277 as its values varied from 1.73 to 1.99 in all models.

278

[Insert Figure 3 here]

279 Table 3 presents that, in model 1, we regressed the nurses' perceptions of work environment

280 against their intentions to quit the nursing profession using SLR analysis. The findings indicated

281 a significant negative influence of working environment perception on the intention to quit

282 among nurses $(b=-.187, p<.05)$; indicating that as nurses' perception of work environment

283 increases, their intentions to quit declines and vice versa. Further, it describes $79 \%$ of the total

284 variation in nurses' intentions to quit $(F=1352.2 ; p<.05)$. Therefore, it is confirmed that

285 nurses' perception of work environment significantly predicts nurses' intention to quit, thus

286 accepting $\mathrm{H}_{1}$. In addition, based on the results of model 2, the formulated regression equation

287 was as follows: intention to quit $=29.053-0.187$ (work environment perception).

288 Table 3 also shows that, in model 2, we regressed the work environment perception of nurses

289 against their communication satisfaction using SLR analysis. The findings present a statistically

290 significant impact of work environment perception on the communication satisfaction among

291 nurses $(b=.764, p<.05)$; indicating that as work environment perception increases among

292 nurses, their communication satisfaction increases proportionately. In addition, work

293 environment explains $84 \%$ of the total variance for communication satisfaction $(F=1950.8 ; p<$

294 .05). Therefore, it is confirmed that nurses' perceptions of work environment significantly

295 predict their satisfaction about communication inside their institution and, thus, $\mathrm{H}_{2}$ was accepted.

296 Based on that results, the formulated regression equation described as: communication

297 satisfaction $=4.454+.764$ (work environment perception).

298 In addition, Table 3 shows that, in model 3, findings of SLR analysis indicated that nurses'

299 communication satisfaction significantly predicts nurses' intentions to quit $(b=-.226, p<.05)$ 
300 and thus $\mathrm{H}_{3}$ was accepted. Further, nurses' communication satisfaction explains $78 \%$ of total

301 variance in their intentions to quit nursing profession $(F=1372.4 ; p<.05)$. The formulated

302 regression equation shown as: intention to quit $=28.311-0.226$ (communication satisfaction).

303 Lastly, as shown in Table 3, in model 4, when communication satisfaction was controlled, the

304 relationship between nurses' work environment perceptions and their intentions to quit became

305 considerably weak ( $b=-.187$ to $b=-.096, p<.05,95 \%$ CI [-.119, -.073]); indicating a significant

306 indirect effect of the nurses' perceptions of work environment on their intention to quit through

307 their communication satisfaction as a mediator variable. In other words, communication

308 satisfaction explains the association between the nurses' work environment perception and their

309 intentions to quit; thus, accepting $\mathrm{H}_{4}$. These results were presented into the MLR's equation as:

310 intention to quit $=29.586-0.096$ (work environment perception) -0.120 (communication

311 satisfaction).

312

[Insert Table 3 here]

313 Figure 4 summarizes and presents the associations among the study variables in a schematic 314 diagram.

315

[Insert Figure 4 here]

316

\section{Discussion}

318 This study investigated the associations between nurses' work environment perception and their satisfaction about communication within the healthcare organization. Additionally, it

320 investigated the impact of these variables on their intention to quit the nursing profession as

321 these were found as determinants of intention to quit among nurses, which in turn, leads to 322 resignation and staff shortage (AbuAlRub et al., 2016; Albougami et al., 2020; Oliveira et al., 323 2017; Özer, et al., 2017).

324 The findings showed that the participants demonstrated a moderate level of positive perception 325 regarding their work environment. These results are congruent with other studies conducted in Saudi Arabia (AlMoosa et al., 2020; Almuhsen, et al., 2017), which showed moderate levels of satisfaction about work environment among multi-national nurses. Concomitantly, international studies show comparable situations with no exceptions (Al-Hamdan et al., 2017; Özer, et al., 2017; Ulusoy \& Polatkan, 2016). However, these modest levels of work environment perception in Saudi Arabia are unexpected when they are compared to the total governmental expenses on 
331 the healthcare delivery system. In 2018, the governmental expenses on healthcare system 332 reached 90 billion Saudi Riyals which constituted about 9.2\% of total governmental budget 333 (Ministry of Health, 2018). However, it is reasonable to link these modest levels of work 334 environment satisfaction with the current reported challenges in Saudi nursing practice. Per 335 Alsufyani et al. (2020), the status quo of nursing practice in Saudi Arabia is facing several 336 challenges including shortage of staff, absence of clear and defined scope of practice, and lack of 337 national and international benchmarking.

338 Likewise, the findings showed that the study's participants ranked their communication 339 satisfaction within KFMC as moderate. Due to the dearth of local studies assessing 340 communication satisfaction among nurses in Saudi Arabia, these findings were compared to 341 international studies and are in line with previous studies (Özer, et al., 2017; Vermeir et al., 342 2018). Although these studies investigated the importance of communication satisfaction and its 343 role in enhancing job satisfaction, quality of care, and nurse retention, they showed moderate 344 levels of communication satisfaction. In addition, these studies described and illustrated the 345 presence of communication gap between top nursing management and bedside nurses. However, 346 this communication gap indicates a presence of centralized management which restricts 347 communication, sharing in decision-making, and professional autonomy. Further, centralized 348 management was also reported by Alsufyani et al. (2020) as one of the challenges in nursing 349 practice in Saudi Arabia. In addition, almost all of healthcare organizations in Saudi Arabia 350 depend heavily on non-Saudi nurses from various nationalities with different native languages 351 such as: English, Hindi, Malayic, Tagalog, Tamil, and Urdu. Hence, it is important to foster 352 communication and feedback within Saudi Arabian healthcare organizations through training 353 programs concerning communication skills.

354 The findings of this study revealed a medium-level of intention to quit among nurses. These 355 findings are consistent with other Saudi Arabian studies (Albougami et al., 2020; Alsaqri et al., 356 2014) and other overseas studies (Bal, 2013; Danayiyen, 2015; Özer, et al., 2017). Based on the 357 situation in Saudi Arabian healthcare organization, which relies heavily on expatriate nurses to 358 deliver care, the findings of this study must be taken seriously to develop and execute systematic 359 strategic plans that are aimed at achieving an attractive nursing work environment, to minimize these confounding rates of intentions to leave the profession among nurses. 
361 On the other hand, the findings showed an affirmative positive association between work

362 environment perception and nurses' satisfaction about communication within healthcare

363 organization. Further, it explained $84 \%$ of the total variance in communication satisfaction

364 among nurses. It was established that if the perception of work environment improves, the

365 communication satisfaction improves proportionately. These findings are congruent with Turkish

366 study conducted by Özer, et al., (2017). Undoubtedly, communication satisfaction is a key

367 ingredient in creating healthy work environment and vice versa. Therefore, it is reasonable to

368 assume that healthy work environment is a cornerstone for establishing skilled communicators.

369 The study's findings offer valuable insight into the link between the work environment

370 perception and the nurses' intentions to quit the nursing profession. The results of this study

371 established that nurses' satisfaction level with their work environment was inversely proportional

372 to their intentions to quit. Specifically, higher the nurses' satisfaction with work environments,

373 the lower the intentions to quit. These findings are consistent with previously conducted studies

374 by Al-Hamdan et al. (2017), Özer, et al. (2017); and Zhang et al. (2014), in Jordan, Turkey, and

375 China, respectively, whereby nurses have linked their intentions to quit mainly to their work

376 environment conditions.

377 Similarly, a negative association has been detected between nurses' satisfaction about

378 communication within their healthcare organization and their intentions of turnover. In other

379 words, it indicated that improving communication strategies could inhibit the intentions to quit

380 nursing profession among nurses. These findings support the assertion of AlMoosa et al. (2020),

381 that fair treatment and satisfied communication climate minimize the nursing shortage. Further,

382 these findings are congruent with the findings of overseas studies; the same association was

383 detected in studies conducted by Özer, et al. (2017) and Vermeir et al. (2018), in Belgium and

384 Turkey. In addition, Mustamil et al. (2014), concluded that nurses' satisfaction about

385 communication is a crucial factor in retaining nurses.

386 Lastly, the mediation effect of communication satisfaction on the association between work

387 environment and intention to quit among nurses was revealed by the findings of this study. These

388 findings affirmed that communication satisfaction explained the relationship between work

389 environment perception and intention to quit among nurses. These findings are supported by the

390 proposed standards of American Association Critical-Care Nurses (AACN) to create healthy

391 nursing work environment (AACN, 2005). These standards portray skilled communication as a 
392 crucial factor for establishing an attractive and healthy work environment, which, in turn, leads

393 to minimizing nurses' intention to quit the profession. In addition, similar findings were reported

394 by Turkish study conducted by Özer, et al. (2017). However, these findings illustrate the

395 importance of effective communication climate on nurses' outcomes.

396 In term of study's limitations, this study was conducted in a specific healthcare organization,

397 King Faisal Medical Complex in Saudi Arabia, with conveniently selected sample, which may

398 minimize the representation of the population. In addition, this study focused on only two factors

399 that were found to inhibit the intention to quit the profession while ignoring other equally

400 important factors such as leadership style, professional promotion, and workplace violation rates.

401 Further, our data in this study was collected through self-administered tools which augment

402 potentiality for bias as the researchers were unable to ensure that nurses reported their own

403 perceptions honestly. Thus, there is a need for future studies with mixed methods or qualitative

404 designs to ensure a wider range of understanding of the phenomenon of quitting the profession

405 among nurses in Saudi Arabia.

406 However, in terms of implications for nursing management, the findings of this study present a

407 novel theoretical framework based on the previous knowledge and literature about the factors

408 that affect nurses' intentions to quit nursing profession and to leave their organizations. The

409 study's findings offer valuable evidence that a healthy work environment and effective

410 communication strategies within a healthcare organization positively influence nurses' retention.

411 These results lead to our recommendation that the shortage of nurses in Saudi Arabia can be

412 managed by appropriate nursing management that enhances communication satisfaction and

413 work environments, as these improvements would reduce nurses' intention to quit. In addition,

414 we emphasize the need for establishing effective communication strategies and channels with

415 periodic assessments to ensure their effectiveness.

416

\section{Conclusion}

418 This study highlighted two important factors affecting the nurses' intentions to quit nursing 419 profession in Saudi Arabia. Modest levels of work environment perception and communication

420 satisfaction among nurses were seen as indicators for further systematic strategic plans to

421 achieve attractive nursing working environment. These factors were found to contribute and

422 predict nurses' intention to leave and resign. In addition, communication climate was established 
423 as a crucial factor in establishing attractive and healthy working environment. This study

424 presents a novel conceptual framework that has been developed based on the previous

425 knowledge and literature for the contributing factors for nurses' intention to quit nursing

426 professional and shortage nurses.

427

\section{Acknowledgements}

429 The authors are very thankful to the Deanship of Scientific Research at King Saud University, 430 Saudi Arabia; all the associated personnel in any reference that contributed in/for the purpose of 431 this research are also acknowledged.

432

433 Funding

434 This study was funded and supported by the Deanship of Scientific Research at King Saud 435 University, Saudi Arabia; through Research Group No. RG-1436017

436

437

438

439

440

441

442

443

444

445

446

447

448

449

450

451 


\section{References}

453 Abdien, M. (2019). Impact of communication satisfaction and work-life balance on employee

454

455

456

457

458

459

460

461

462

463

464

465

466

467

468

469

470

471

472

473

474

475

476

477

478

479

480

481 turnover intention. Journal of Tourism Theory and Research, 228-238. doi: $10.24288 / \mathrm{jttr} .526678$

Aboshaiqah, A. (2016). Strategies to address the nursing shortage in Saudi Arabia. International Nursing Review, 63(3), 499-506. doi:10.1111/inr.12271

AbuAlRub, R., El-Jardali, F., Jamal, D., \& Al-Rub, N. A. (2016). Exploring the relationship between work environment, job satisfaction, and intent to stay of Jordanian nurses in underserved areas. Applied Nursing Research, 31, 19-23. doi:10.1016/j.apnr.2015.11.014

Admi, H., Moshe-Eilon, Y., Sharon, D., \& Mann, M. (2018). Nursing students' stress and satisfaction in clinical practice along different stages: A cross-sectional study. Nurse Education Today, 68, 86-92. doi:10.1016/j.nedt.2018.05.027

Al-Ahmadi, H. (2014). Anticipated nurses' turnover in public hospitals in Saudi Arabia. The International Journal of Human Resource Management, 25(3), 412-433. doi: $10.1080 / 09585192.2013 .792856$

Albougami, A. S., Almazan, J. U., Cruz, J. P., Alquwez, N., Alamri, M. S., Adolfo, C. A., \& Roque, M. Y. (2020). Factors affecting nurses' intention to leave their current jobs in Saudi Arabia. International Journal of Health Sciences, 14(3). Retrieved from https://ijhs.org.sa/index.php/journal/article/view/3814

Al-Hamdan, Z., Manojlovich, M. \& Tanima, B. (2017) Jordanian nursing work environments, intent to stay, and job satisfaction. Journal of Nursing Scholarship, 49 (1), 103-110. doi:10.1111/jnu.12265

AlMoosa, M., Hassanein, S. E., Alnems, A., Abdrbo, A. A., Minguez, O., \& Ghadheeb, F. A. (2020). Perception of Nurses Work Environment in Tertiary Care Hospital in Saudi Arabia. American Journal of Nursing Science, 9(1), 23. doi:10.11648/j.ajns.20200901.14

Almuhsen, F., Alkorashy, H., Baddar, F., \& Qasim, A. (2017). Work environment characteristics as perceived by nurses in Saudi Arabia. International Journal of Advanced Nursing Studies, 6(1), 45. doi:10.14419/ijans.v6i1.7453

Alonazi, N., \& Omar, M. (2013). Factors affecting the retention of nurses. Saudi Medical Journal, 34(3), 288-294. 
482 Alsaqri, S. (2014). A Survey of Intention to Leave, Job Stress, Burnout and Job Satisfaction

483

484

485

486

487

488

489

490

491

492

493

494

495

496

497

498

499

500

501

502

503

504

505

506

507

508

509

510

among Nurses Employed in the Ha'il Region's Hospitals in Saudi Arabia (Doctoral dissertation). Retrieved from Google Scholar. RMIT University.

Alshammari, M., Duff, J., \& Guilhermino, M. (2019). Barriers to nurse-patient communication in Saudi Arabia: An integrative review. BMC Nursing, 18(1). doi:10.1186/s12912-019$0385-4$

Alsufyani, A. M., Alforihidi, M. A., Almalki, K. E., Aljuaid, S. M., Alamri, A. A., \& Alghamdi, M. S. (2020). Linking the Saudi Arabian 2030 vision with nursing transformation in Saudi Arabia: Roadmap for nursing policies and strategies. International Journal of Africa Nursing Sciences, 3(34), 1-6. doi:10.1016/j.ijans.2020.100256

Al-Zayyer, W. (2003). The Effectiveness of Recruitment and Retention Strategies and the Severity of Recruitment and Retention Barriers of Staff Nurses in Selected Tertiary Care Hospitals Saudi Arabia (Doctoral dissertation). Retrieved from Google Scholar. George Mason University.

American Association of Critical-Care Nurses (2005). AACN standards for establishing and sustaining healthy work environments: a journey to excellence (2nd ed.). Aliso Viejo: CA: American Association of Critical-Care Nurses

Andersson, R. (2018). Employee Communication Responsibility: Its Antecedents and Implications for Strategic Communication Management. International Journal of Strategic Communication, 13(1), 60-75. doi:10.1080/1553118x.2018.1547731

Bal, C. G. (2013). A field study on communication satisfaction in health institutions. Selcuk University: The Journal of Social Economic Research, 13(25), 107-125

Baron, R. M., \& Kenny, D. A. (1986). The moderator-mediator variable distinction in social psychological research: Conceptual, strategic, and statistical considerations. Journal of Personality and Social Psychology, 51(6), 1173-1182. doi:10.1037//0022-3514.51.6.1173

Cammann C, Fichman M, Jenkins D, Klesh J (1979). The Michigan organizational assessment questionnaire. Unpublished manuscript, University of Michigan, Ann Arbor.

Danayiyen, A. (2015). Impact of new communication media to corporate communication satisfaction in the hospitals. (Master's Thesis). Istanbul, Turkey: Okan University. 
511 Doleman, G., Twigg, D., \& Bayes, S. (2020). A comparison of middle managers' and paediatric 512 nurses' satisfaction with organisational communication. Journal of Nursing Management. 513 doi:10.1111/jonm.13064

514 Downs, C. W., \& Hazen, M. D. (1977). A Factor Analytic Study of Communication Satisfaction. 515 Journal of Business Communication, 14(3), 63-73. doi:10.1177/002194367701400306

516 Falatah, R., \& Conway, E. (2019). Linking relational coordination to nurses' job satisfaction, 517 affective commitment and turnover intention in Saudi Arabia. Journal of Nursing 518 Management, 27(4), 715-721. doi:10.1111/jonm.12735

519 Field, A. P. (2018). Discovering statistics using IBM SPSS statistics. Thousand Oaks, CA: Sage 520 Publications.

521 Gray, J. R., Grove, S. K., \&amp; Sutherland, S. (2017). Burns and Grove's the practice of 522 nursing research: Appraisal, synthesis, and generation of evidence. St. Louis, MO: 523 Elsevier.

524 Greenbaum, H. H., Clampitt, P., \& Willihnganz, S. (1988). Organizational Communication.

525 Management Communication Quarterly, 2(2), 245-282.

526 doi: $10.1177 / 0893318988002002008$

527 Hua W, Omar B (2016). Examining communication satisfaction, confucian work dynamism and 528 job satisfaction: a comparative study of international and domestic hotels in Hainan, China. 529 The Journal of the South East Asia Research Centre for Communications and Humanities. 530 8, 105-27. Retrieved from: http://search.taylors.edu.my/documents/journals/2016-8531 1/SEARCH-2016-8-1-J6.pdf

532 Kang, K. H., Han, Y. H., \& Kang, S. J. (2012). Relationship Between Organizational 533 Communication Satisfaction and Organizational Commitment among Hospital Nurses. $534 \quad$ Journal of Korean Academy of Nursing Administration, 18(1), 13.

535 doi:10.11111/jkana.2012.18.1.13

536 Kohun S. Business environment. Ibadan: University Press Kyko OC (2005). Instrumentation: 537 Know Yourself and Others Longman Dictionary of Contemporary English (2003) 3rd 538 edition: Harloa Pearson Educational Limited. 1992.

539 Lake ET (1998). Advances in understanding and predicting nurse turnover. Res Sociol Health 540 Care.147-72. 
541 Lake, E. T. (2002). Development of the practice environment scale of the nursing work index.

542 Research in Nursing \& Health, 25(3), 176-188. doi:10.1002/nur.10032

543 Masum, A. K., Azad, M. A., Hoque, K. E., Beh, L., Wanke, P., \& Arslan, Ö. (2016). Job

544 satisfaction and intention to quit: An empirical analysis of nurses in Turkey. PeerJ, 4.

545 doi: $10.7717 /$ peerj.1896

546 Ministry of Health. (2018). Statistical yearbook. Available at:

547 https://www.moh.gov.sa/en/Ministry/Statistics/book/Pages/default.aspx/ [accessed 01 July $548 \quad 2020]$.

549 Nantsupawat, A., Kunaviktikul, W., Nantsupawat, R., Wichaikhum, O., Thienthong, H., \&

550 Poghosyan, L. (2016). Effects of nurse work environment on job dissatisfaction, burnout,

551 intention to leave. International Nursing Review, 64(1), 91-98. doi:10.1111/inr.12342

552 Oliveira, D. R., Griep, R. H., Portela, L. F., \& Rotenberg, L. (2017). Intention to leave

553 profession, psychosocial environment and self-rated health among registered nurses from

554 large hospitals in Brazil: A cross-sectional study. BMC Health Services Research, 17(1).

555 doi:10.1186/s12913-016-1949-6

556 Özer, Ö, Şantaş, F., Şantaş, G., \& Şahin, D. S. (2017). Impact of nurses' perceptions of work

557 environment and communication satisfaction on their intention to quit. International

$558 \quad$ Journal of Nursing Practice, 23(6). doi:10.1111/ijn.12596

559 Pongton P, Suntrayuth S. Communication Satisfaction, Employee Engagement, Job Satisfaction, 560 and Job Performance in Higher Education Institutions. ABAC Journal. 39(3). 90-110.

561 Raziq, A., \& Maulabakhsh, R. (2015). Impact of Working Environment on Job Satisfaction.

562 Procedia Economics and Finance, 23, 717-725. doi:10.1016/s2212-5671(15)00524-9

563 Saeed, K. (1995). Factors which influence nurses' intention to leave the hospital, Riyadh city,

564 Saudi Arabia. Journal of King Saud University, 7(2), 85-105.

565 Shultz, K. S., Whitney, D. J., \& Zickar, M. J. (2014). Measurement theory in action: Case $566 \quad$ studies and exercises. New York: Routledge/ Taylor \& Francis Group.

567 Suliman, W. (2009). Leadership styles of nurse managers in a multinational environment.

568 Nursing Administration Quarterly, 33(4), 301-309. doi: 10.1097/NAQ.0b013e3181b9dd35

569 Tsai, Y. (2011). Relationship between Organizational Culture, Leadership Behavior and Job

570 Satisfaction. BMC Health Services Research, 11(1). doi:10.1186/1472-6963-11-98 
571 Ulusoy, H., \& Polatkan, R. (2016). Assessment of the nurses' work environment using the 572 nursing work index scale. Cumhuriyet Medical Journal, 38(4), 246-257. 573 doi: $10.7197 / \mathrm{cmj} . v 38 \mathrm{i} 3.5000196868$

574 Vermeir, P., Blot, S., Degroote, S., Vandijck, D., Mariman, A., Vanacker, T., . . Vogelaers, D. 575 (2018). Communication satisfaction and job satisfaction among critical care nurses and 576 their impact on burnout and intention to leave: A questionnaire study. Intensive and 577 Critical Care Nursing, 48, 21-27. doi:10.1016/j.iccn.2018.07.001

578 World Medical Association (2013). Declaration of Helsinki: Ethical Principles for Medical 579 Research Involving Human Subjects. JAMA, 310(20), 2191.

$580 \quad$ doi:10.1001/jama.2013.281053

581 Zhang, L. F., You, L. M., Liu, K., Zheng, J., Fang, J. B., Lu, M. M., ... Bu, X. Q. (2014). The 582 association of Chinese hospital work environment with nurse burnout, job satisfaction, and 583 intention to leave. Nursing Outlook, 62(2), 128-137. doi:10.1016/j.outlook.2013.10.010 


\section{Table 1 (on next page)}

Selected demographic characteristics of participants 
Table 1: Selected demographic characteristics of participants

\begin{tabular}{|c|c|c|c|}
\hline \multirow[t]{2}{*}{ Variable } & \multicolumn{3}{|c|}{ Participants $(n=367)$} \\
\hline & & $\mathbf{F}$ & $\%$ \\
\hline \multirow[t]{2}{*}{ Gender } & Male & 78 & $21.3 \%$ \\
\hline & Female & 289 & $78.7 \%$ \\
\hline \multirow[t]{3}{*}{ Age groups } & $25-30$ years & 71 & $19.4 \%$ \\
\hline & $31-40$ years & 263 & $71.7 \%$ \\
\hline & $41-50$ years & 33 & $8.9 \%$ \\
\hline \multirow{3}{*}{$\begin{array}{l}\text { Number of years worked as a } \\
\text { nurse }\end{array}$} & $2-10$ Years & 103 & $28.1 \%$ \\
\hline & $11-20$ Years & 236 & $64.3 \%$ \\
\hline & $21-30$ Years & 28 & $7.6 \%$ \\
\hline \multirow[t]{4}{*}{ Nursing Area } & Med/Surg & 57 & $15.6 \%$ \\
\hline & $\mathrm{OB} / \mathrm{GYN}$ & 71 & $19.3 \%$ \\
\hline & Critical & 33 & $9.0 \%$ \\
\hline & Other & 206 & $56.1 \%$ \\
\hline \multirow[t]{4}{*}{ Nationality } & Saudi & 87 & $23.7 \%$ \\
\hline & Filipino & 153 & $41.7 \%$ \\
\hline & Indian / Pakistani & 93 & $25.3 \%$ \\
\hline & Others & 34 & $9.3 \%$ \\
\hline
\end{tabular}


Table 2 (on next page)

Descriptive statistics and inter-correlations between work environment, communication satisfaction, and intention to quit 
Table 2: Descriptive statistics and inter-correlations between work environment, communication 1 satisfaction, and intention to quit

\begin{tabular}{lcccc}
\hline Variables & Mean \pm SD & 1 & $\mathbf{2}$ & $\mathbf{3}$ \\
\hline Intention to Quit (1) & $2.47 \pm 1.38$ & $(1)$ & & \\
Working environment (2) & $3.72 \pm 0.63$ & $-.602-* *$ & $(1)$ \\
Communication Satisfaction (3) & $3.71 \pm 0.65$ & $-.581-* *$ & $.613^{* *}$ & $(1)$
\end{tabular}

$* * p<.05$ (2-tailed). 
Table 3 (on next page)

Results of regression analyses -models summaries 
Table 3. Results of regression analyses - model summaries

1

\begin{tabular}{|c|c|c|c|c|c|c|c|c|}
\hline Model & Outcome variable & Predictors & $\boldsymbol{b}$ & Std. error & $\boldsymbol{\beta}$ & $t$ & $p$ & CI 95\% \\
\hline 1 & Intention to quit & $\begin{array}{c}\quad(\text { constant }) \\
\text { Working environment } \\
\mathrm{R}=.89, \mathrm{R}^{2}=.79 \\
F=1352.2 ; p<.05 \\
\text { Durbin Watson }=1.99\end{array}$ & $\begin{array}{l}29.053 \\
-.187\end{array}$ & $\begin{array}{l}.597 \\
.005\end{array}$ & -.887 & $\begin{array}{r}48.669 \\
-36.772\end{array}$ & $\begin{array}{l}<.05 \\
<.05\end{array}$ & $\begin{array}{c}{[27.879,30.227]} \\
{[-.197,-.177]}\end{array}$ \\
\hline 2 & $\begin{array}{l}\text { Communication } \\
\text { satisfaction }\end{array}$ & $\begin{array}{c}\text { (constant) } \\
\text { Working environment } \\
\mathrm{R}=.92, \mathrm{R}^{2}=.84 \\
F=1950.8 ; p<.05 \\
\text { Durbin Watson }=1.97\end{array}$ & $\begin{array}{l}4.454 \\
.764\end{array}$ & $\begin{array}{l}2.025 \\
.017\end{array}$ & .918 & $\begin{array}{c}.814 \\
15.460\end{array}$ & $\begin{array}{r}.028 \\
<.05\end{array}$ & $\begin{array}{c}{[.471,8.436]} \\
{[.730, .798]}\end{array}$ \\
\hline 3 & Intention to quit & $\begin{array}{c}\text { (constant) } \\
\text { Communication satisfaction } \\
\mathrm{R}=.88, \mathrm{R}^{2}=.79 \\
F=1372.4 ; p<.05 \\
\text { Durbin Watson }=1.73\end{array}$ & $\begin{array}{l}28.311 \\
-.226\end{array}$ & $\begin{array}{l}.573 \\
.006\end{array}$ & -.889 & $\begin{array}{r}49.424 \\
-37.046\end{array}$ & $\begin{array}{l}<.05 \\
<.05\end{array}$ & $\begin{array}{c}{[27.184,29.437]} \\
{[-.238,-.214]}\end{array}$ \\
\hline 4 & Intention to quit & $\begin{array}{c}\text { (constant) } \\
\text { Work environment } \\
\text { Communication satisfaction } \\
\mathrm{R}=.91, \mathrm{R}^{2}=.822 \\
F=843.303 ; p<.05\end{array}$ & $\begin{array}{l}29.586 \\
-.096 \\
-.120\end{array}$ & $\begin{array}{l}.550 \\
.012 \\
.014\end{array}$ & $\begin{array}{l}-.455 \\
-.472\end{array}$ & $\begin{array}{l}53.804 \\
-8.173 \\
-8.477\end{array}$ & $\begin{array}{l}<.05 \\
<.05 \\
<.05\end{array}$ & $\begin{array}{c}{[28.505,30.668]} \\
{[-.119,-.073]} \\
{[-.147,-.092]}\end{array}$ \\
\hline
\end{tabular}




\begin{tabular}{|l|l|l|l|l|l|l|l|}
\hline & & Durbin Watson = 1.854 & & & & & \\
\hline
\end{tabular}


Figure 1

Lake's Model of Nurse Turnover (Lake, 1998)

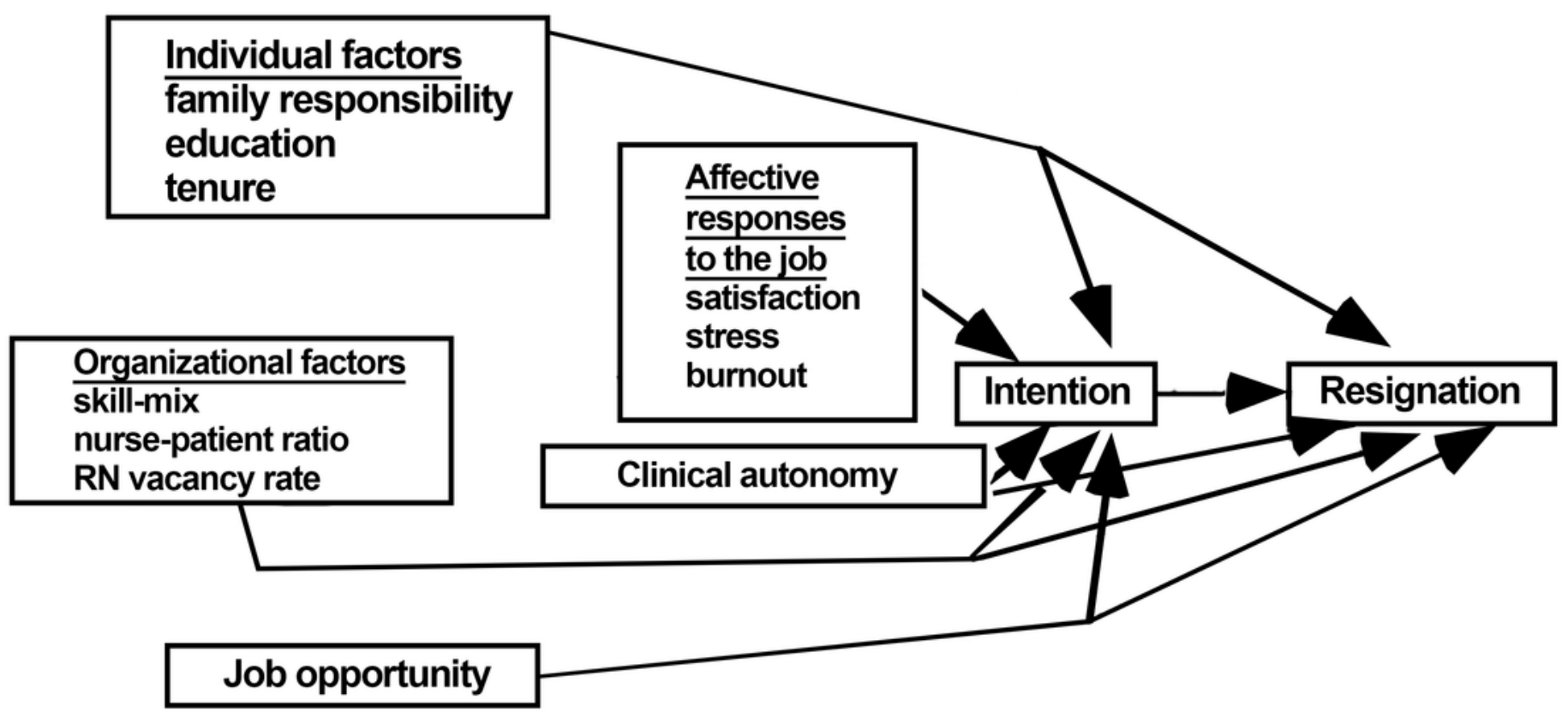


Figure 2

The conceptual model for the current study

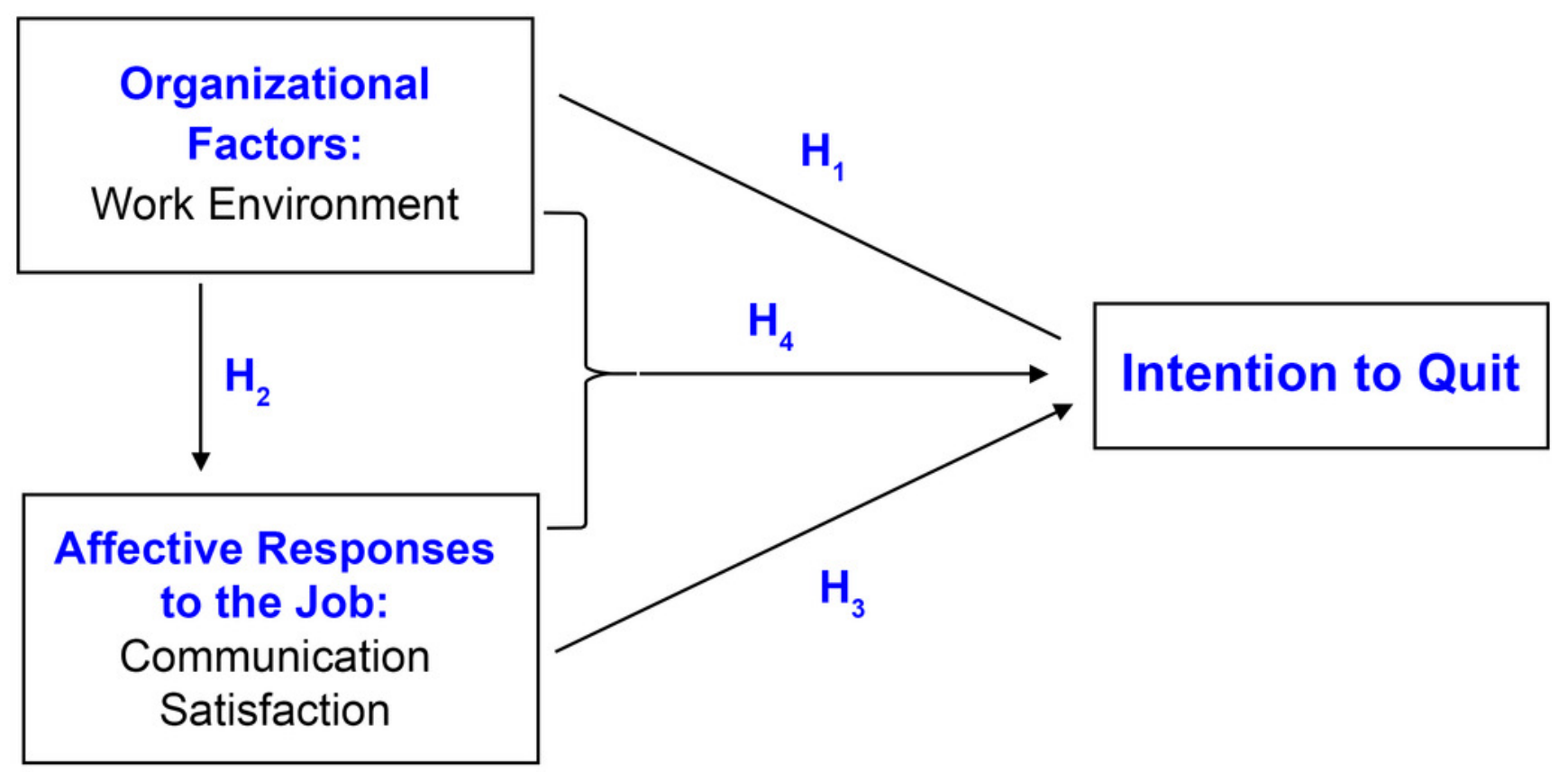


Figure 3

Normal probability plot (P-P) of the regression standardized residuals

Normal P-P Plot of Regression Standardized Residual

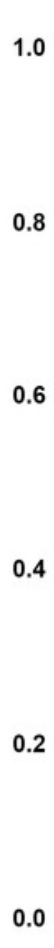

Dependent Variable: Intern

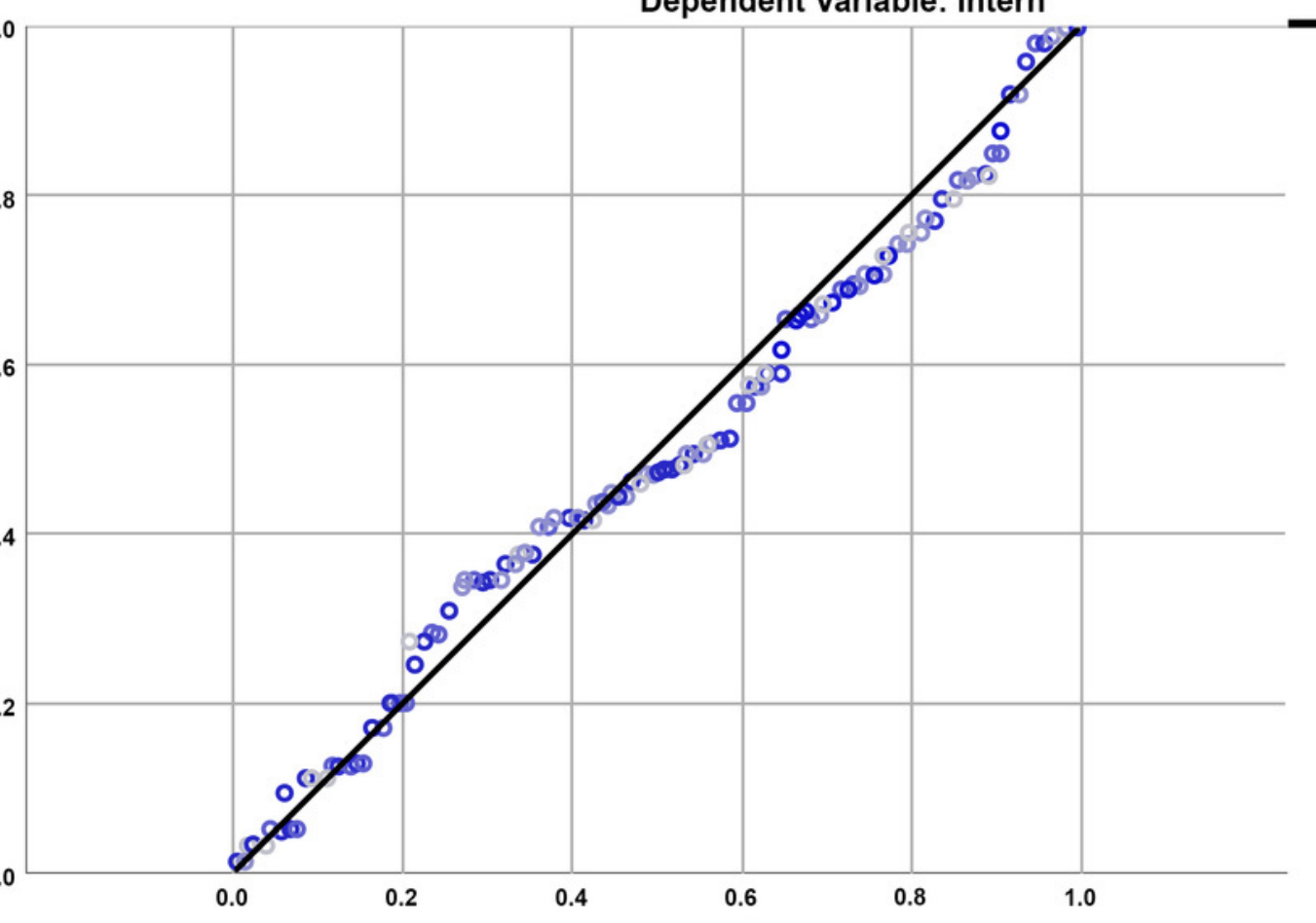

Expected Cum ProbObserved Cum Prob Expected Cum Prob Normal Line - Observed Cum Prob Normal Line 


\section{Figure 4}

\section{Summary of the relationships between study's variables}

(a): the association between work environment and communication satisfaction

(b): the association between work environment and intention to quit

(c): the association between communication satisfaction and intention to quit

(c'): the indirect effect of work environment on intention to quit through communication satisfaction as a mediator. 


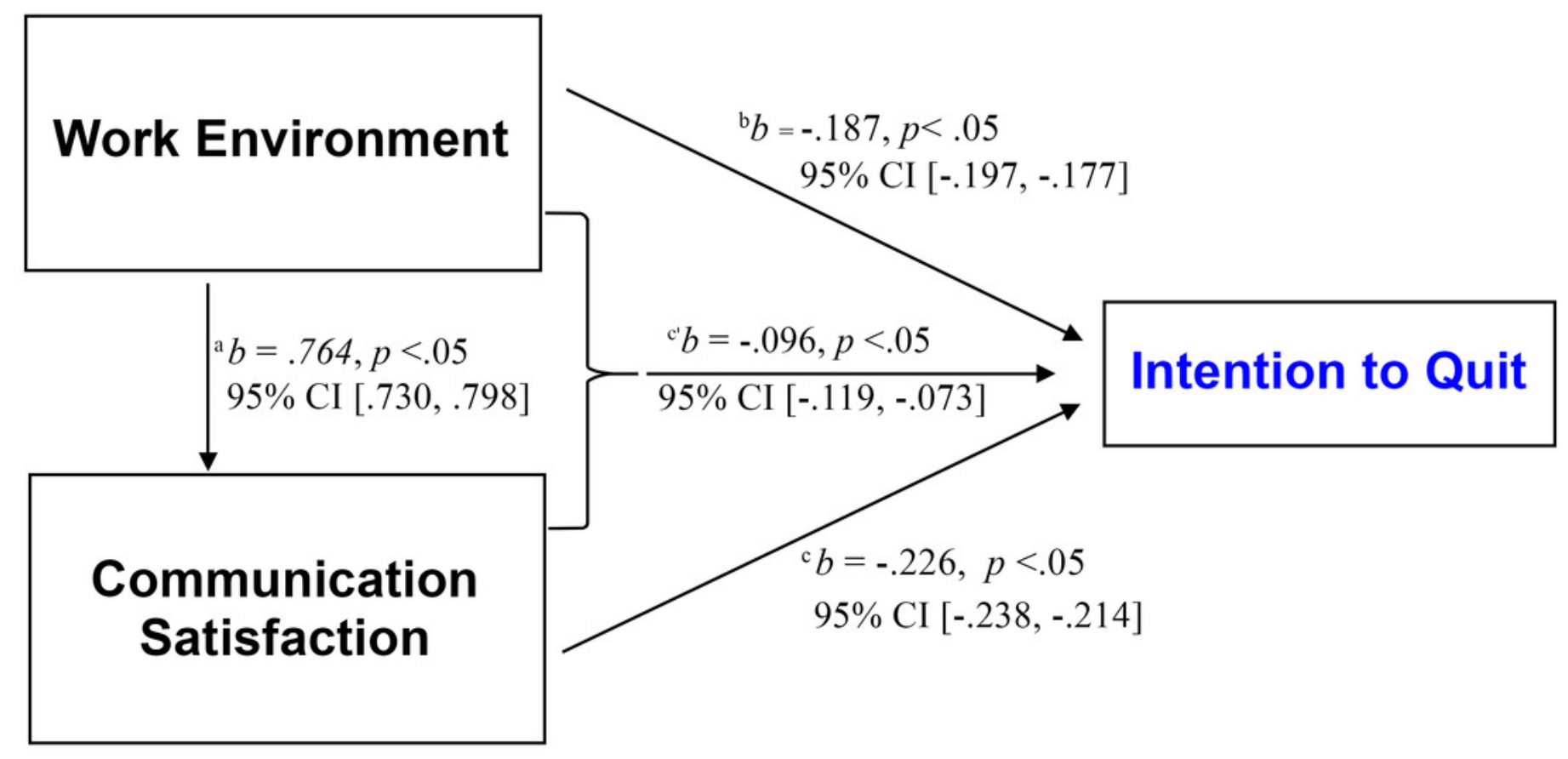

